\title{
Acute dietary nitrate supplementation improves arterial endothelial function at high altitude: A double-blinded randomized controlled cross over study
}

\author{
Emily Bakker a , Harald Engan ${ }^{\text {b, c, } 1}$, Alexander Patrician ${ }^{\text {b }}$, Erika Schagatay ${ }^{\text {b, d }}$, \\ Trine Karlsen ${ }^{\text {a, e }}$, Ulrik Wisløff a, Svein Erik Gaustad ${ }^{\text {a, * }}$
}

${ }^{a}$ K.G. Jebsen Center of Exercise in Medicine at the Department of Circulation and Medical Imaging, Norwegian University of Science and Technology, Faculty of Medicine, Trondheim, Norway

b Department of Health Sciences, Mid Sweden University, Östersund, Sweden

${ }^{c}$ LHL-Klinikkene Røros, LHL-Health, Norway

d Swedish Winter Sports Research Center, Mid Sweden University, Östersund, Sweden

e St. Olav's University Hospital, Trondheim, Norway

\section{A R T I C L E I N F O}

\section{Article history:}

Received 8 May 2015

Received in revised form

23 August 2015

Accepted 24 August 2015

Available online 29 August 2015

\section{Keywords:}

Nitric oxide

Beetroot juice

Field-study

FMD

Flow mediated dilation

Nepal

Altitude medicine

\begin{abstract}
A B S T R A C T
Introduction: Dietary nitrate $\left(\mathrm{NO}_{3}^{-}\right)$supplementation serves as an exogenous source of nitrite $\left(\mathrm{NO}_{2}^{-}\right)$and nitric oxide (NO) through the $\mathrm{NO}_{3}^{-}-\mathrm{NO}_{2}^{-}-\mathrm{NO}$ pathway, and may improve vascular functions during normoxia. The effects of $\mathrm{NO}_{3}^{-}$supplementation in healthy lowlanders during hypobaric hypoxia are unknown.

Purpose: Determine the effect of acute oral $\mathrm{NO}_{3}^{-}$supplementation via beetroot juice (BJ) on endothelial function (flow mediated dilation; FMD) in lowlanders at $3700 \mathrm{~m}$.

Methods: FMD was measured using ultrasound and Doppler in the brachial artery of 11 healthy subjects (4 females, age $25 \pm 5$ yrs; height $1.8 \pm 0.1 \mathrm{~m}$, weight $72 \pm 10 \mathrm{~kg}$ ) sojourning to high altitude. In a randomized, double-blinded crossover study design, FMD was measured $3 \mathrm{~h}$ after drinking $\mathrm{BJ}$ ( $5.0 \mathrm{mmol}$ $\mathrm{NO}_{3}^{-}$) and placebo (PL; $0.003 \mathrm{mmol} \mathrm{NO}_{3}^{-}$) supplementation at $3700 \mathrm{~m}$, with a 24-h wash out period between tests. FMD was also measured without any BJ supplementation pre-trek at $1370 \mathrm{~m}$, after 5 days at $4200 \mathrm{~m}$ and upon return to $1370 \mathrm{~m}$ after 4 weeks of altitude exposure (above $2500 \mathrm{~m}$ ). The altitude exposure was interrupted by a decent to lower altitude where subjects spent two nights at $1370 \mathrm{~m}$ before returning to altitude again.

Results: Ten subjects completed the $\mathrm{NO}_{3}^{-}$supplementation. FMD (mean $\pm \mathrm{SD}$ ) pre-trek value was $6.53 \pm 2.32 \%$ at $1370 \mathrm{~m}$. At $3700 \mathrm{~m}$ FMD was reduced to $3.84 \pm 1.31 \%(\mathrm{p}<0.01)$ after PL supplementation but was normalized after receiving BJ $(5.77 \pm 1.14 \%(p=1.00)$. Eight of the subjects completed the interrupted 4-week altitude stay, and their FMD was lower at $4200 \mathrm{~m}$ (FMD $3.04 \pm 2.22 \%$ ) and at postaltitude exposure to $1370 \mathrm{~m}$ (FMD $3.91 \pm 2.58 \%$ ) compared to pre-trek FMD at $1370 \mathrm{~m}$.

Conclusion: Acute dietary $\mathrm{NO}_{3}^{-}$supplementation may abolish altitude-induced reduction in endothelial function, and can serve as a dietary strategy to ensure peripheral vascular function in lowland subjects entering high altitude environments.
\end{abstract}

๑) 2015 Elsevier Inc. All rights reserved.

\footnotetext{
* Corresponding author. Norwegian University of Science and Technology, Department of Circulation and Medical Imaging, Prinsesse Kristinas gt. 3, 7006 Trondheim, Norway.

E-mail address: Svein.e.gaustad@ntnu.no (S.E. Gaustad).

1 Joint first author.
}

\section{Introduction}

At high altitude (HA) proper acclimatization is crucial to maintain physiological functions. Preservation of the vascular system is vital for this process, due to its importance for oxygen $\left(\mathrm{O}_{2}\right)$ delivery to the tissues and regulation of perfusion pressure to different organs. The definition of a normal vascular response to HA is unclear and there is no general consensus in the literature of how $\mathrm{HA}$ affects 
the arterial endothelial function and vascular tone. Conflicting reports of arterial vasoconstriction or vasodilation upon HA exposure are possibly due to variation in the study designs (population, type and duration of hypoxia) and measurement sites (pulmonary, cerebral, peripheral vasculature) $[1,2]$. Nevertheless, a key player in obtaining proper endothelial function is nitric oxide (NO). It has been suggested that natives of Tibet living at HA partly have adapted to altitude by NO related mechanisms, and it has been shown that they exhibit high levels of circulating bioactive NO products [4]. Moreover, the combination of high concentrations of circulating bioactive NO products and low hemoglobin is associated with increased forearm blood flow in this population [4]. In native lowlanders, the role of circulating vasoactive nitrogen oxides during acclimatizing to $\mathrm{HA}$ was assessed, showing that nitrate $\left(\mathrm{NO}_{3}^{-}\right)$, nitrite $\left(\mathrm{NO}_{2}^{-}\right)[5,6]$ and cyclic guanosine monophosphate (cGMP) [5], biomarkers of NO production and activity, were elevated upon HA acclimatization.

$\mathrm{NO}$ is formed through both the $\mathrm{L}$-arginine pathway and the $\mathrm{NO}_{3}^{-}-$ $\mathrm{NO}_{2}^{-}$-NO pathway. However in an $\mathrm{O}_{2}$ depleted environment, the $\mathrm{L}-$ arginine pathway has a decreased ability to generate NO [8-10], which makes the $\mathrm{NO}_{3}^{-}-\mathrm{NO}_{2}^{-}-\mathrm{NO}$ pathway more important. Ingested inorganic $\mathrm{NO}_{3}^{-}$is rapidly absorbed from the gut to the blood and then metabolized to $\mathrm{NO}_{2}^{-}$by salivary bacteria [9]. This pathway can restore NO production in hypoxic conditions as there is increased generation and use of $\mathrm{NO}_{3}^{-}$and $\mathrm{NO}_{2}^{-}$[9]. This is due to increased reduction to $\mathrm{NO}_{2}^{-}$and $\mathrm{NO}$ by deoxyhemoglobin and deoxymyoglobin [11-13], which are more available at $\mathrm{HA}$ when blood $\mathrm{O}_{2}$ saturation is decreased.

At sea level dietary $\mathrm{NO}_{3}^{-}$supplementation is effective for optimizing vascular function, resulting in a reduction of blood pressure (BP) [14-17] and improvement of endothelial function with $0.5-4 \%$ increase in flow-mediated dilation (FMD) in healthy subjects after acute supplementation $[18,19]$. Beetroot juice (BJ), known to contain high doses of $\mathrm{NO}_{3}^{-}[17,20]$, has been demonstrated to have a vasoprotective role [17] and improved FMD after a high fat meal [21]. Based on the positive effect of dietary $\mathrm{NO}_{3}^{-}$supplementation on endothelial function at sea level, its' effectiveness in optimizing endothelial function under hypobaric hypoxic conditions should be explored. In this study, the primary aim was to investigate the effects of dietary $\mathrm{NO}_{3}^{-}$supplementation on endothelial function during hypobaric hypoxia at HA in lowlanders. The secondary aim was to investigate the effect of prolonged HA exposure on endothelial function.

It was hypothesized that 1) FMD at $3700 \mathrm{~m}$ would be depressed compared to pre-trek FMD at $1370 \mathrm{~m}, 2$ ) that dietary $\mathrm{BJ} \mathrm{NO}_{3}^{-}$supplementation normalizes FMD at $3700 \mathrm{~m}$, and 3) FMD will remain suppressed compared to pre-trek FMD at $1370 \mathrm{~m}$ after a interrupted 4-week exposure to HA (above $2500 \mathrm{~m}$ ).

\section{Materials and methods}

This study was performed in Kathmandu and the Rolwaling Valley, Nepal. It was ethically approved by Swedish Research Council and Nepal Health Research Council and performed according to the Helsinki declaration.

\subsection{Subjects}

A total of 11 healthy lowlanders ( 4 female, $25 \pm 5 \mathrm{yrs}, 1.8 \pm 0.1 \mathrm{~m}$, $72 \pm 10 \mathrm{~kg}$ ) participated in this field study. The subjects received oral information and read and signed an informed consent. None had been at altitude within 12 months prior to the expedition. A baseline measurement was completed for 10 of the subjects, as one did not follow subject restrictions prior to this measurement. A different subject did not participate in the BJ supplementation due to logistical reasons, 10 subjects completed BJ supplementation. Three subjects did not complete the expedition, rendering a total of 8 subjects for final measurement after 4 weeks at HA.

\subsection{Study timeline}

FMD was measured 5 times at 3 different altitudes within 39 days of the trekking expedition (Fig. 1). To avoid potential effects of chronobiology, all measurements were obtained in the morning. Pre-trek measure (Test 1 ) was taken at $1370 \mathrm{~m}$ in Kathmandu, one day after arrival. HA was considered as elevations above 2500 m (4 of the 5 weeks of the expedition).

\subsubsection{Acute measurements}

The $\mathrm{NO}_{3}^{-}$supplementation protocol (BJ/placebo (PL)) took place on days 7 and 8 at $3700 \mathrm{~m}$ (Test 2/3), after the subjects had spent 3 days walking from $1525 \mathrm{~m}$ to $3700 \mathrm{~m}$ and after one day residing at $3700 \mathrm{~m}$.

\subsubsection{Measurements during altitude exposure}

The endothelial function was measured at $4200 \mathrm{~m}$ (Test 4) on day 10 , after 5 days above $2500 \mathrm{~m}$. Post-HA measures were performed one day after return flight to Kathmandu at $1370 \mathrm{~m}$ (Test 5) on day 39 of the trekking expedition, after 4 weeks of HA exposure (above $2500 \mathrm{~m}$ ) which was interrupted by a decent to lower altitude where subjects spent two nights at $1370 \mathrm{~m}$. Most travel between elevations occurred by walking, with the exception of nine hours bus transportation to the Rolwaling valley (1525 m) on day 2 . Additional motorized transportation was used on day 21 ( 9 h bus from Rolwaling valley) and day 23 ( $1 \mathrm{~h}$ plane to Khumbu valley at $2860 \mathrm{~m}$ ) due to extreme weather conditions preventing the subjects from climbing a mountain pass between these valleys (two days altitude interruption to $1370 \mathrm{~m}$ ). The subjects were transported from the Khumbu valley to Kathmandu by plane ( $1 \mathrm{~h}$ ) on the final day of the trek (day 38).

\subsection{Tests and measurements}

FMD was assessed in the brachial artery using a $12-\mathrm{MHz}$ Doppler probe and ultrasound imaging (Vivid I, GE Healthcare, USA) following current guidelines [22]. All tests were performed according to a standardized procedure, and consisted of FMD technique to estimate NO-mediated vasodilation, as well as recording of heart rate (HR), BP, and arterial oxygen saturation $\left(\mathrm{SaO}_{2}\right)$.

\subsubsection{Subject preparation}

To avoid measurement bias, subjects avoided caffeine, tobacco and exercise on the testing days and food intake $3 \mathrm{~h}$ prior to measurements [22]. Subjects avoided mouthwash and tooth brushing on the BJ/PL test days in order not to wash out lingual bacteria important for $\mathrm{NO}_{3}^{-}$reduction [23]. Prior to the measurement, subjects were questioned about their compliance to the study restrictions. In the field subjects were tested inside cabins, and a combination of wood ovens, propane heaters and down sleeping bags were used to control ambient temperature and keep subjects warm (BJ/PL test, room temperature $20 \pm 2{ }^{\circ} \mathrm{C}$ ).

\subsubsection{FMD procedure}

An occlusion cuff (SC10, D.E. Hokanson Co., Bellevue, USA) was placed on the non-dominant forearm distal to the measuring site and three lead ECG electrodes on shoulders and chest [24]. The measuring site for all FMD measures was above the anticubital fossa, with the arm extended [24]. Once the subject and measurement equipment were prepared, the subjects were requested to 


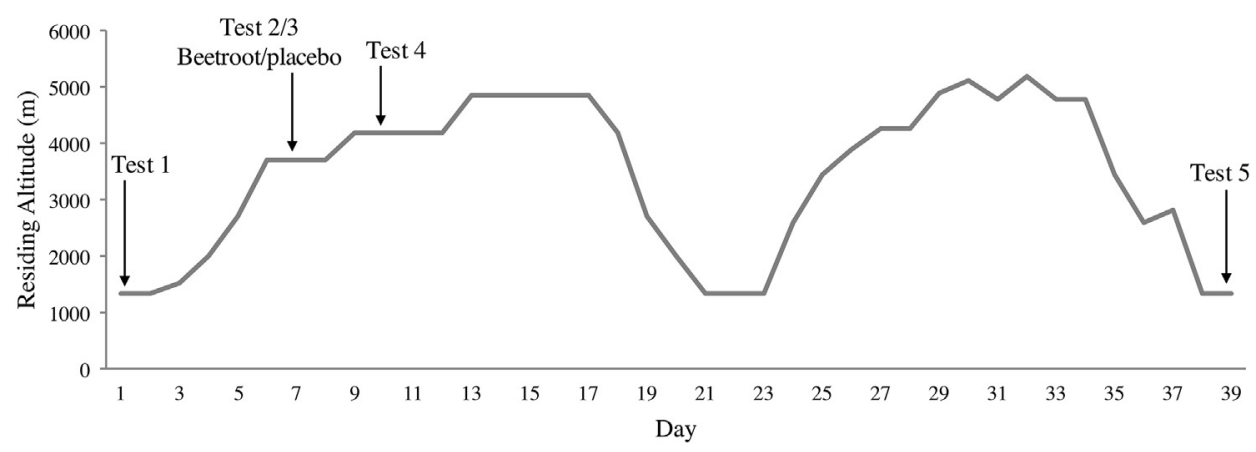

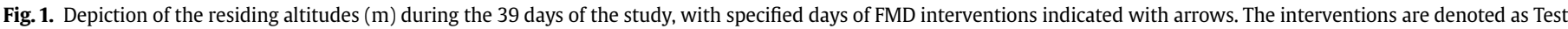

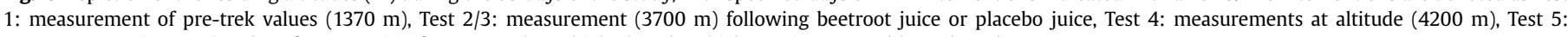
measurements $(1370 \mathrm{~m})$ 1-day after returning from 4-weeks at high altitude which was interrupted by 2 days decent to $1370 \mathrm{~m}$.

relax in a supine position.

After 10 min total supine resting the FMD measurement began, and baseline diameter and blood velocity of the brachial artery were recorded. Once baseline measures had been recorded, the occlusion cuff was inflated to $>250 \mathrm{mmHg}$ for $5 \mathrm{~min}$ [22]. Upon release of the cuff occlusion the resultant peak in blood flow was recorded (within $10 \mathrm{~s}$ ) using Doppler and the artery diameter image was recorded for $3 \mathrm{~min}$ in 30 -s intervals.

\subsubsection{Blood pressure, heart rate and oxygen saturation procedure}

Before FMD measurements, and after 5 min of supine rest, $3 \mathrm{BP}$ and HR measurements were taken on the dominant arm in 1-min intervals using an automatic BP cuff (Omron Healthcare, Lake Forest, USA). During the vascular occlusion and reactive hyperemia phases of the FMD measurement, $\mathrm{SaO}_{2}$ and $\mathrm{HR}$ were manually recorded on 1-min intervals using a pulse oximeter (OnyxVantage, Nonin Medical, Plymouth, USA), for a total of 8 recordings.

\subsubsection{Beetroot/placebo juice supplementation procedure}

In a double-blinded randomized-cross over manner, subjects drank $70 \mathrm{ml}$ organic concentrated beetroot juice shots (James White Drinks Ltd., Suffolk, UK) containing either $5.0 \mathrm{mmol} \mathrm{NO}_{3}^{-}(\mathrm{BJ})$ or $\mathrm{NO}_{3}^{-}$depleted beetroot juice shots (PL) containing $0.003 \mathrm{mmol}$ $\mathrm{NO}_{3}^{-}$on two consecutive days, with a 24 -h washout period between doses [17]. In the $\mathrm{PL}$ juice, $\mathrm{NO}_{3}^{-}$was removed via ion-exchanging resin, while the color, taste, smell and texture remained indistinguishable from the BJ servings [25]. The FMD measurement period commenced $3 \mathrm{~h}$ after supplementation, in order to assess FMD during anticipated peak $\mathrm{NO}_{3}^{-}$and $\mathrm{NO}_{2}^{-}$concentration [14,17].

\subsubsection{Dehydration scoring}

The subjects self-assessed dehydration by scoring urine color from 0 to 8 . A score of 3 or less indicated hydrated state and a score greater than 3 indicated dehydration. Urine color is closely correlated with urine osmolality, and an acceptable measure in field studies [26].

\subsection{Data analysis}

The FMD measurements were evaluated blinded from the intervention. Artery diameter analysis (intima to intima) was performed using caliper measurement $(0.1 \mathrm{~mm}$ resolution) using the peak of the ECG R wave of the cardiac cycle for timing. Three repetitions were made per cardiac cycle and 3 cardiac cycles per time point. The mean calculated to represent the artery diameter and each subject's peak artery diameter post occlusion was chosen individually based on maximum dilation [22]. Baseline and peak blood flow $\left(\mathrm{mm} \cdot \mathrm{s}^{-1}\right)$ were estimated from Doppler waveform for velocity.

The FMD (\%) was calculated from the difference in peak and baseline artery diameter (maximum dilation) divided by baseline. Shear rate $\left(\mathrm{s}^{-1}\right)$ was estimated by dividing peak blood flow by peak artery diameter, and further used to account for mechanical stress with a resultant FMD to shear stress ratio (normalized FMD; nFMD) [27]. The mean FMD was calculated as the sum of the FMD (\%) from $30 \mathrm{~s}$ to $180 \mathrm{~s}$ post-occlusion divided by the total number of time points [19]. The flow stimulus received by the artery during reactive hyperemia was expressed as the ratio of peak blood flow to baseline blood flow [17].

An average of the two most similar values was used for calculation of $\mathrm{BP}$ and $\mathrm{HR}$, while for $\mathrm{SaO}_{2}$ calculations an average of the 8recorded values was used.

\subsubsection{Statistical analysis}

For statistical analysis IBM SPSS 21 statistics software (SPSS Inc, Chicago, USA) was used, and Graph Pad Prism 6 (GraphPad Software Inc., San Diego, USA) for graph figures. Normality was tested using the Shapiro-Wilk test. For dietary $\mathrm{NO}_{3}^{-}$supplementation data repeated measures ANOVA with Bonferroni correction was used to compare means of baseline, BJ and PL. Liner Mixed Models with Compound Symmetry using pairwise comparison of estimated marginal means with Bonferroni correction was used for comparison of Test 1, 4, and 5. For all tests significance was set to $\mathrm{p}<0.05$ and a trend denoted when $\mathrm{p}<0.1$.

\section{Results}

\subsection{Endothelial function at altitude after acute supplementation of beetroot juice}

At HA of $3700 \mathrm{~m}$ FMD was reduced after PL supplementation to $3.84 \pm 1.31 \%$ in comparison to the $1370 \mathrm{~m}$ pre-trek levels at $6.53 \pm 2.32 \%(\mathrm{p}<0.01)$. At $3700 \mathrm{~m}$, BJ supplementation restored FMD to $5.77 \pm 1.14 \%$, similar to pre-trek levels at $1370 \mathrm{~m}(\mathrm{p}=1.00)$ (Fig. 2A). Similar increase from BJ supplementation was found examining nFMD, where nFMD was $0.025 \pm 0.007 \% \cdot s$ at $1370 \mathrm{~m}$ pre-trek, a lower value of $0.015 \pm 0.004 \% \cdot s$ with PL $(p<0.01)$, and restored to $0.023 \pm 0.009 \% \cdot s$ with $\mathrm{BJ}(\mathrm{p}=1.00)$ (Fig. $2 \mathrm{~B}$ ). Mean FMD, the average dilation over $3 \mathrm{~min}$, was $1.46 \pm 1.81 \%$ lower with PL $(1.51 \pm 1.78 \%)$ supplementation compare to BJ supplementation $(2.91 \pm 2.11 \% ; \mathrm{p}<0.01)$.

The flow stimulus tended ( $\mathrm{p}=0.085$ ) to be larger during $\mathrm{BJ}$ supplementation, with a difference of $15.8 \pm 24.2 \%$ compared to PL at $3700 \mathrm{~m}$ (Table 1 ). No differences were observed when comparing 

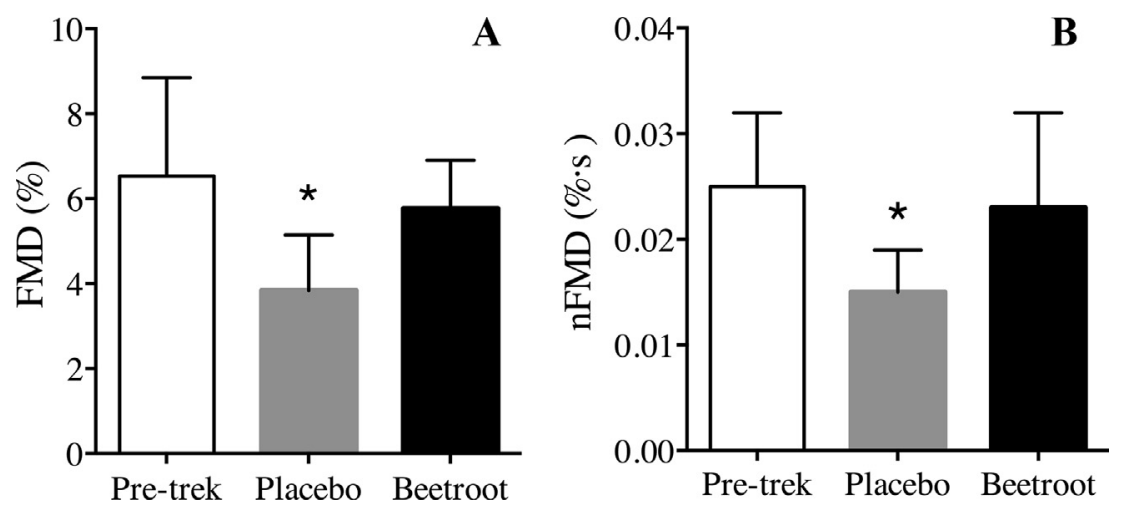

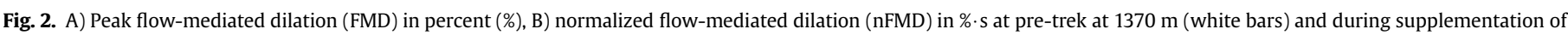

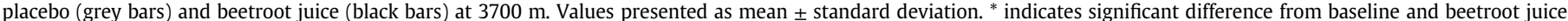
$(\mathrm{p}<0.01)$.

Table 1

Acute vascular function with beetroot or placebo supplementation at $3700 \mathrm{~m}$.

\begin{tabular}{lcc}
\hline & Placebo & Beetroot \\
\hline Baseline artery diameter $(\mathrm{mm})$ & $3.86 \pm 0.56$ & $3.84 \pm 0.62$ \\
Peak artery diameter $(\mathrm{mm})$ & $4.00 \pm 0.57$ & $4.06 \pm 0.63$ \\
Baseline blood flow $\left(\mathrm{mm} \mathrm{s}^{-1}\right)$ & $808.2 \pm 169.0$ & $743.4 \pm 159.5$ \\
Peak blood flow $\left(\mathrm{mm} \mathrm{s}^{-1}\right)$ & $1001.0 \pm 196.2$ & $1060.6 \pm 281.5$ \\
Flow stimulus & $1.25 \pm 0.18$ & $1.43 \pm 0.28$ \\
Shear rate $\left(\mathrm{s}^{-1}\right)$ & $250.7 \pm 40.3$ & $268.9 \pm 86.8$ \\
\hline
\end{tabular}

Data are presented as mean \pm standard deviation. $\mathrm{mm}=$ millimeters; $\mathrm{s}=$ seconds.

BJ and PL supplementation at $3700 \mathrm{~m}$ to baseline blood flow, peak blood flow, shear rate, or baseline and peak artery diameter (Table 1).

\subsection{Endothelial function during altitude exposure}

Compared to pre-trek at $1370 \mathrm{~m}$, FMD remained reduced during altitude exposure at $4200 \mathrm{~m}$, and when measured at $1370 \mathrm{~m}$ after 4 weeks of interrupted high $(>2500 \mathrm{~m})$ altitude exposure $(\mathrm{p}<0.05$, estimated marginal mean \pm SD, Table 2). The nFMD reflected similar decreases (Table 2). There was a trend of reduction $(\mathrm{p}=0.091)$ in baseline blood flow from the first day of the expedition at $1370 \mathrm{~m}$ (Test 1) to post-expedition measurements at $1370 \mathrm{~m}$ (Test 5; Table 2).

\subsection{Heart rate, blood pressure and arterial oxygen saturation}

The mean HR at $4200 \mathrm{~m}$ was $65 \pm 11$ beats $\cdot$ minutes $^{-1}$, which was significantly higher than at all other test points. Pre-trek HR at $1370 \mathrm{~m}$ was $58 \pm 11$ beats $\cdot$ minutes $^{-1}, 12 \pm 15 \%$ lower than the HR at $4200 \mathrm{~m}$ and $14 \pm 18 \%$ higher than the post-expedition HR at $1370 \mathrm{~m}$
( $\mathrm{p}<0.05)$. Mean $\mathrm{SaO}_{2}$ at $4200 \mathrm{~m}$ was $84.9 \pm 2.9 \%$, and it was reduced by $12.4 \%$ from both pre-trek and post-expedition values, at $97.3 \pm 2.9 \%$ and $97.3 \pm 3.2 \%$, respectively $(\mathrm{p}<0.01)$. No differences were observed comparing BJ and PL supplementation at $3700 \mathrm{~m}$ with regard to the basic physiological measures, $\mathrm{HR}, \mathrm{SaO}_{2}$, systolic blood pressure, diastolic BP and mean arterial pressure (Table 3).

\subsection{Dehydration score}

Mean dehydration score was similar at all test locations, whereas individual subject values ranged from 1 to 8 . Dehydration scores were not completed for all testing days/locations. Mean values were $3.4 \pm 2.0$ at $3700 \mathrm{~m}$ (day 8), $3.8 \pm 2.0$ at $4200 \mathrm{~m}$ (day 10) and $3.8 \pm 2.2$ post-expedition (day 38 ).

\section{Discussion}

The principal finding of this investigation was that dietary $\mathrm{NO}_{3}^{-}$ supplementation with $\mathrm{BJ}$ restored FMD of the brachial artery to pretrek levels by enhanced NO-mediated dilation in healthy

Table 3

Physiological variables with beetroot and placebo supplementation at $3700 \mathrm{~m}$.

\begin{tabular}{lcc}
\hline & Placebo & Beetroot \\
\hline Heart rate $(\mathrm{bpm})$ & $70 \pm 18$ & $68 \pm 16$ \\
$\mathrm{SaO}_{2}(\%)$ & $87.9 \pm 4.0$ & $87.3 \pm 4.8$ \\
$\mathrm{SBP}(\mathrm{mmHg})$ & $115 \pm 15$ & $115 \pm 13$ \\
$\mathrm{DBP}(\mathrm{mmHg})$ & $70 \pm 14$ & $73 \pm 14$ \\
$\mathrm{MAP}(\mathrm{mmHg})$ & $86 \pm 13$ & $86 \pm 14$ \\
\hline
\end{tabular}

Data are presented as mean \pm standard deviation. $\mathrm{SaO}_{2}$ : arterial oxygen saturation SBP: systolic blood pressure, DBP: diastolic blood pressure, MAP: mean arterial pressure.

Table 2

Vascular function at $1370 \mathrm{~m}$ and $4200 \mathrm{~m}$.

\begin{tabular}{|c|c|c|c|}
\hline & Test $1(1370 \mathrm{~m}) \mathrm{n}=10$, day 1 & Test $4(4200 \mathrm{~m}) \mathrm{n}=11$, day 10 & Test $5(1370 \mathrm{~m}) \mathrm{n}=8$, day 39 \\
\hline FMD (\%) & $6.53 \pm 2.32$ & $3.04 \pm 2.22^{*}$ & $3.91 \pm 2.58^{*}$ \\
\hline $\mathrm{nFMD}(\% \cdot \mathrm{s})$ & $0.025 \pm 0.007$ & $0.011 \pm 0.007^{*}$ & $0.016 \pm 0.010$ \\
\hline Baseline artery diameter (mm) & $3.78 \pm 0.56$ & $3.72 \pm 0.56$ & $3.67 \pm 0.57$ \\
\hline Peak artery diameter $(\mathrm{mm})$ & $4.02 \pm 0.56$ & $3.83 \pm 0.55$ & $3.82 \pm 0.57$ \\
\hline Baseline blood flow $\left(\mathrm{mm} \mathrm{s}^{-1}\right)$ & $770.5 \pm 177.6$ & $722.9 \pm 172.0$ & $644.6 \pm 192.2$ \\
\hline Peak blood flow $\left(\mathrm{mm} \mathrm{s}^{-1}\right)$ & $1042.4 \pm 205.6$ & $1039.7 \pm 199.7$ & $958.4 \pm 221.0$ \\
\hline Flow stimulus & $1.40 \pm 0.3$ & $1.46 \pm 0.3$ & $1.52 \pm 0.3$ \\
\hline Shear rate $\left(\mathrm{s}^{-1}\right)$ & $264.3 \pm 59.2$ & $273.5 \pm 58.1$ & $254.0 \pm 61.9$ \\
\hline
\end{tabular}

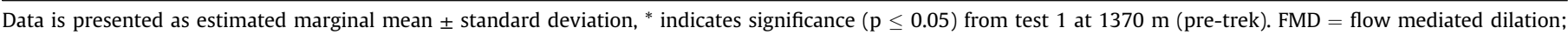
$\mathrm{nFMD}=$ flow mediated dilation normalized for share rate, $\mathrm{mm}=$ millimeter; $\mathrm{s}=$ seconds . 
lowlanders while at HA. The secondary finding was that NOmediated dilation of the brachial artery was reduced during altitude exposure and after returning from $\mathrm{HA}$.

\subsection{Improved endothelial function after dietary nitrate supplementation}

The application of $\mathrm{NO}_{3}^{-}$rich $\mathrm{BJ}$ at $3700 \mathrm{~m}$ abolished the hypobaric hypoxia induced endothelial reduction seen with PL supplementation, and restored FMD to $1370 \mathrm{~m}$ pre-trek values (Fig. 2). The improved FMD after dietary $\mathrm{NO}_{3}^{-}$supplementation at $\mathrm{HA}$ is in line with several studies conducted under normobaric conditions, of subjects with both normal and reduced baseline FMD [17-19,21]. To the authors knowledge this is the first study to describe this effect under hypobaric hypoxic conditions during an expedition with healthy lowlanders. Dietary $\mathrm{NO}_{3}^{-}$supplementation may therefore represent a promising strategy for maintaining endothelial function in native lowlanders at HA.

The $\mathrm{BJ}$ dose used in this study was within the range of previous studies $[18,19,28,29]$. After application of $5 \mathrm{mmol} \mathrm{NO}_{3}^{-}$(BJ) in this study, mean FMD increased by $1.5 \pm 0.2 \%$ which is slightly more than a $0.5 \%$ increase in mean FMD found with smaller dose (2.94 $\left.\mathrm{mmol} \mathrm{NO}_{3}^{-}\right)$in healthy subjects at sea level [19]. In addition, the peak FMD increased by $1.9 \pm 1.0 \%$ in the present study, which is less than a $4 \%$ increase in peak FMD after application of a larger dose (12.45 $\left.\mathrm{mmol} \mathrm{NO}_{3}^{-}\right)$in healthy subjects at sea level [18]. Thus, it might be inferred that the dose used in this study was above a potential threshold to elicit a detectable response, but too low to elicit a potential maximal response. However, it should be noted that even if there seems to be a dose dependent relationship of dietary $\mathrm{NO}_{3}^{-}$supplementation on vascular function and plasma $\mathrm{NO}_{2}^{-}$ at sea level [14], it is not known whether such a dose-response relationship is evident at HA. The increased FMD found $3 \mathrm{~h}$ after $\mathrm{NO}_{3}^{-}$supplementation may imply that this time frame is sufficient to induce detectable changes in endothelial function. This is also indirectly supported by other studies showing increased plasma $\mathrm{NO}_{3}^{-}$and $\mathrm{NO}_{2}^{-}$concentrations and cardiovascular changes $1,5-3 \mathrm{~h}$ following $\mathrm{NO}_{3}^{-}$supplementation $[14,17,21]$.

It should be mentioned that dietary $\mathrm{NO}_{3}^{-}$supplementation does not seem to always improve FMD [30]. However, the effect on endothelial function seems to be more prevalent in individuals already experiencing a dysfunction [21], as well as for protecting against ischemia induced dysfunction [17,31]. In the current study, subjects with normal FMD at baseline measure had reduced FMD within days of exposure to $\mathrm{HA}$, implying that dietary $\mathrm{NO}_{3}^{-}$supplementation may be effective for individuals showing reduced vascular function during HA exposure. In contrast to studies conducted at sea level [14-17], $\mathrm{NO}_{3}^{-}$supplementation did not lower BP in our study. The lack of BP reduction despite the increased FMD might be related to less sensitivity of the BP method. While FMD is mostly dependent on NO-activity, BP is also affected by several other factors at altitude such as alteration of sympathetic activity and elevated circulating catecholamine [32] and endothelin levels [33].

$\mathrm{BJ} \mathrm{NO}_{3}^{-}$supplementation has become a popular strategy to improve exercise capacity at sea level [34] and lately there are studies that have addressed the effect of dietary $\mathrm{BJ} \mathrm{NO}_{3}^{-}$supplementation on exercise performance during hypobaric [35] -and normobaric hypoxia [36]. The latter study showed that $\mathrm{NO}_{3}^{-}$supplementation did not enhance altitude running performance in well trained athletes. Whether the FMD response to $\mathrm{NO}_{3}^{-}$supplementation at altitude is dependent on exercise level remains unclear, and should be addressed in future studies.

4.1.1. Mechanism of improved FMD after BJ supplementation 4.1.1.1. Endothelial function. The increased FMD after dietary $\mathrm{NO}_{3}^{-}$ supplementation is likely related to increased plasma $\mathrm{NO}_{3}^{-}$and $\mathrm{NO}_{2}^{-}$ concentrations [17]. Hypoxic conditions decreases NO synthesis from L-arginine [8-10], which likely occurred in our subject at HA, while the $\mathrm{NO}_{3}^{-}-\mathrm{NO}_{2}^{-}-\mathrm{NO}$ pathway is likely facilitated at low $\mathrm{O}_{2}$ tension levels [9]. After ingestion of dietary $\mathrm{NO}_{3}^{-}$, the conversion $\mathrm{NO}_{2}^{-}$to NO occurs through a variety of mechanisms including eNOS and xanthine oxidoreductase mediated reduction of $\mathrm{NO}_{2}^{-}$to $\mathrm{NO}$ $[16,37]$. In addition, deoxyhaemoglobin and deoxymyoglobin $[9,11,13]$ have been shown to be important facilitators for the reduction of dietary $\mathrm{NO}_{3}^{-}$. The decreased hemoglobin oxygenation at $\mathrm{HA}\left(\mathrm{SaO}_{2} 84.9 \%\right.$ at $4200 \mathrm{~m}$ in the present study) increases the content of deoxyhaemoglobin, thereby likely facilitating the reduction of $\mathrm{NO}_{3}^{-}$to $\mathrm{NO}_{2}^{-}$[11]. In sum, during hypoxic conditions dietary $\mathrm{NO}_{3}^{-}$supplementation is optimized due to increased reduction of dietary $\mathrm{NO}_{3}^{-}$to $\mathrm{NO}$ [7,9], and the increased $\mathrm{NO}$ availability for smooth muscle action likely results in vasodilation $[9,23]$.

4.1.1.2. Stimulus differences. The second potential mechanism for FMD increase after BJ supplementation is an altered FMD shear stimulus. However, cuff occlusion was identical for both supplementations. In addition, there were no differences in baseline or peak blood flow, or shear rate, but there was a trend of increased flow stimulus ratio following BJ supplementation compared to PL. BJ may affect blood flow [20,30,38], therefore acting as a potential difference for FMD stimulus. As urine color, indicating hydration status, was not analyzed both test days, any differences in hydration may have affected the FMD result in addition to a potential effect of $\mathrm{BJ}$ on vascular volume.

\subsection{Endothelial function and high altitude exposure}

The reduced FMD during altitude exposure found in this study is in line with earlier reports of altered FMD during both short (hours) exposure to normobaric hypoxia [39,40] and longer (days) exposure to HA [41]. However, in previous findings, subject groups displaying endothelial dysfunction were those previously determined to be vulnerable to HA [39-41]. Therefore a novel finding in this study is that FMD is reduced in healthy lowlanders at HA. Moreover, the subjects of our study displayed a FMD at $1370 \mathrm{~m}$ that was comparable to age-matched lowlanders at sea level [24]. In the literature there is there is no data directly comparable to our results, but interestingly it was shown that FMD in metabolic syndrome patients was reduced from $7.4 \%$ to $3.8 \%$ after 3 weeks at $1700 \mathrm{~m}[41]$. However, it is not known if disease or altitude specific mechanisms could be involved in this reduction.

The decreased FMD measured at HA was apparent after descending from HA (Test 5), suggesting a loss of endothelial function. The recovery time for normal NO availability is unknown, and whether HA creates long term endothelial damage initiating development of cardiovascular disease, or if damages recover after complete rehydration or some months at lowland [41], should be investigated in long-term studies. In long-term studies, various cardiovascular parameters should also be taken into account, since it is known that long-term HA exposure is associated with prolonged elevated sympathetic activity [42] and transient changes of cardiac mass, function and energy metabolism [43] after return to sea level. Additionally, it should also be noted that levels of circulating vasoactive nitrogen oxides have been shown to increase during acclimatization to HA [5,6], and it remains to be investigated how this relates to endothelial function in the long-term in native lowlanders.

\subsubsection{Mechanisms for reduced FMD with altitude exposure}

The positive effect of dietary $\mathrm{NO}_{3}^{-}$supplementation on FMD at HA (Test 2) supports the possibility of an underlying imbalance of 
vasoconstrictors and dilatators as discussed above [20]. Although not addressed in this study, there are other mechanisms that may have contributed to reduced endothelial dilation, including erythropoietin (EPO), up-regulation of the vasoconstrictor endothelin, and antioxidant status $[40,44]$. A factor that plays a critical role in a number of genetic responses controlling physiological effects in response to $\mathrm{HA}$ is the $\mathrm{O}_{2}$-sensitive transcription factor hypoxiainducible factor HIF- $1 \alpha$ [45]. The role of HIF- $1 \alpha$ in the decreased FMD seen at $4200 \mathrm{~m}$ in conjunction with the significant reduction in $\mathrm{SaO}_{2}$ is unclear, but Janocha et al. [6] reported that a fall in oxyhemoglobin saturation was consistent with an increase in HIF upregulated proteins, endothelin-1 and EPO. In Tibetan highlanders, low levels of hemoglobin are reported to be associated with HIF-2 $\alpha$ expression [46], and increased forearm blood flow [4]. Since the same population also exhibits high levels of circulating bioactive NO products [4], NO related mechanisms seems to play an important role in adaption to HA.

Another possible mechanism for reduced FMD may be differences in blood flow. It could have been that the combination of altitude induced diuresis and altitude induced erythropoiesis may have changed blood flow properties [41]. However, no significant changes in velocity of blood flow during rest were found in this study. This is similar to previous findings for velocity of blood flow, however is in contrast to volumetric blood flow $\left(\mathrm{mL} \cdot \mathrm{min}^{-1}\right)$ that is reported as decreased in the brachial artery at HA, compared to both measurements at sea level and at $1310 \mathrm{~m}[1,47]$.

\section{Study strengths and limitations}

The double-blinded randomized controlled crossover design is a key in the overall strength of this study. With this design the bias was reduced, as each subject served as his or her own control. This was especially important due to the high variability in response to altitude and supplement interventions. Due to the field study design a strong external validity is present, while some limitations exist in experimental design. A limitation of this study is lack of $12 \mathrm{~h}$ complete fasting prior to the FMD measurements, but with subjects serving as their own control, this effect is limited. Furthermore overall modifications in diet (versus pre-expedition) were not taken into account, which could have effects on FMD [22]. Another limitation of this field study is the lack of blood plasma samples that were not obtained due to logistical reasons. This could have enabled a correlation analysis of FMD values with plasma $\mathrm{NO}_{3}^{-}$and $\mathrm{NO}_{2}^{-}$levels. Finally, since baseline measurements were not conducted at sea level prior to the expedition, the present study did not evaluate if FMD at $1370 \mathrm{~m}$ in Kathmandu would differ from sea level values.

\section{Conclusion}

This study showed that acute dietary $\mathrm{NO}_{3}^{-}$supplementation abolished the reduction in endothelial function found at HA in healthy subjects. Dietary $\mathrm{NO}_{3}^{-}$supplementation may therefore represent a promising strategy for maintaining endothelial function in native lowlanders at HA. It should however be noted that since the reduction in FMD was found at $4200 \mathrm{~m} \mathrm{2-3}$ days after $\mathrm{NO}_{3}^{-}$supplementation, that the duration of the positive effects from BJ supplementation in HA remains unclear. Since FMD after returning from four weeks of HA was reduced, potential prolonged effects on endothelial function from long-term HA exposure deserves further investigation.

\subsection{Clinical implications}

The results from this study imply a reduced capacity for peripheral blood flow regulation in healthy native lowlanders at HA which may impact cardiovascular health during and after HA exposure. The potential clinical implications of continued reduction in vascular function at altitude and upon descent should be further investigated. Ingestion of $\mathrm{NO}_{3}^{-}$rich vegetables may represent a lowcost dietary strategy to improve vascular function for altitude dwellers.

\section{Funding source}

The Department of Circulation and Medical Imaging, K. G Jebsen Center for Exercise in Medicine, the Global Health Program at the Faculty of Medicine at NTNU, and the Swedish Centre for Research in Sports (CIF).

\section{Conflicts of interest}

The authors have no conflicts of interest.

\section{Acknowledgments}

The authors would like to thank the volunteers for participating in the study despite straining conditions. We would also like to thank the guides and staff of Rolwaling Excusions for the arrangements and support while in Nepal, Dr Arjun Karki at Patan Academy, Nepal for his kind help to set up the study.

\section{References}

[1] V. Dumais, P. Nault, A. Tsertsvadze, T.L. Forbes, Conduit vessel blood flow during the trek to Mount Everest base camp, Wilderness Environ. Med. 22 (2011) 309-315.

[2] M.L. Blitzer, S.D. Lee, M.A. Creager, Endothelium-derived nitric oxide mediates hypoxic vasodilation of resistance vessels in humans, Am. J. Physiol. 271 (1996) H1182-H1185.

[4] S.C. Erzurum, S. Ghosh, A.J. Janocha, W. Xu, S. Bauer, N.S. Bryan, J. Tejero, C. Hemann, R. Hille, D.J. Stuehr, M. Feelisch, C.M. Beall, Higher blood flow and circulating NO products offset high-altitude hypoxia among Tibetans, Proc. Natl. Acad. Sci. U. S. A. 104 (2007) 17593-17598.

[5] D.Z. Levett, B.O. Fernandez, H.L. Riley, D.S. Martin, K. Mitchell, C.A. Leckstrom, C. Ince, B.J. Whipp, M.G. Mythen, H.E. Montgomery, M.P. Grocott, M. Feelisch, G. Caudwell Extreme Everest Research, The role of nitrogen oxides in human adaptation to hypoxia, Sci. Rep. 1 (2011) 109.

[6] A.J. Janocha, C.D. Koch, M. Tiso, A. Ponchia, A. Doctor, L. Gibbons, B. Gaston, C.M. Beall, S.C. Erzurum, Nitric oxide during altitude acclimatization, N. Engl. J. Med. 365 (2011) 1942-1944.

[7] B.S. Zuckerbraun, P. George, M.T. Gladwin, Nitrite in pulmonary arterial hypertension: therapeutic avenues in the setting of dysregulated arginine/nitric oxide synthase signalling, Cardiovasc Res. 89 (2011) 542-552.

[8] L.P. McQuillan, G.K. Leung, P.A. Marsden, S.K. Kostyk, S. Kourembanas, Hypoxia inhibits expression of eNOS via transcriptional and posttranscriptional mechanisms, Am. J. Physiol. 267 (1994) H1921-H1927.

[9] J.O. Lundberg, E. Weitzberg, M.T. Gladwin, The nitrate-nitrite-nitric oxide pathway in physiology and therapeutics, Nat. Rev. Drug Discov. 7 (2008) $156-167$.

[10] D.J. Stuehr, Mammalian nitric oxide synthases, Biochim. Biophys. Acta 1411 (1999) 217-230.

[11] K. Cosby, K.S. Partovi, J.H. Crawford, R.P. Patel, C.D. Reiter, S. Martyr, B.K. Yang, M.A. Waclawiw, G. Zalos, X. Xu, K.T. Huang, H. Shields, D.B. Kim-Shapiro, A.N. Schechter, R.O. Cannon 3rd, M.T. Gladwin, Nitrite reduction to nitric oxide by deoxyhemoglobin vasodilates the human circulation, Nat. Med. 9 (2003) 1498-1505.

[12] J.O. Lundberg, M. Govoni, Inorganic nitrate is a possible source for systemic generation of nitric oxide, Free Radic. Biol. Med. 37 (2004) 395-400.

[13] S. Shiva, Z. Huang, R. Grubina, J. Sun, L.A. Ringwood, P.H. MacArthur, X. Xu, E. Murphy, V.M. Darley-Usmar, M.T. Gladwin, Deoxymyoglobin is a nitrite reductase that generates nitric oxide and regulates mitochondrial respiration, Circ. Res. 100 (2007) 654-661.

[14] V. Kapil, A.B. Milsom, M. Okorie, S. Maleki-Toyserkani, F. Akram, F. Rehman, S. Arghandawi, V. Pearl, N. Benjamin, S. Loukogeorgakis, R. Macallister, A.J. Hobbs, A.J. Webb, A. Ahluwalia, Inorganic nitrate supplementation lowers blood pressure in humans: role for nitrite-derived NO, Hypertension 56 (2010) 274-281.

[15] L.T. Coles, P.M. Clifton, Effect of beetroot juice on lowering blood pressure in free-living, disease-free adults: a randomized, placebo-controlled trial, Nutr. J. 11 (2012) 106 
[16] D.A. Hobbs, N. Kaffa, T.W. George, L. Methven, J.A. Lovegrove, Blood pressurelowering effects of beetroot juice and novel beetroot-enriched bread products in normotensive male subjects, Br. J. Nutr. 108 (2012) 2066-2074.

[17] A.J. Webb, N. Patel, S. Loukogeorgakis, M. Okorie, Z. Aboud, S. Misra, R. Rashid, P. Miall, J. Deanfield, N. Benjamin, R. MacAllister, A.J. Hobbs, A. Ahluwalia, Acute blood pressure lowering, vasoprotective, and antiplatelet properties of dietary nitrate via bioconversion to nitrite, Hypertension 51 (2008) 784-790.

[18] C. Heiss, C. Meyer, M. Totzeck, U.B. Hendgen-Cotta, Y. Heinen, P. Luedike, S. Keymel, N. Ayoub, J.O. Lundberg, E. Weitzberg, M. Kelm, T. Rassaf, Dietary inorganic nitrate mobilizes circulating angiogenic cells, Free Radic. Biol. Med. 52 (2012) 1767-1772.

[19] C.P. Bondonno, X. Yang, K.D. Croft, M.J. Considine, N.C. Ward, L. Rich, I.B. Puddey, E. Swinny, A. Mubarak, J.M. Hodgson, Flavonoid-rich apples and nitrate-rich spinach augment nitric oxide status and improve endothelial function in healthy men and women: a randomized controlled trial, Free Radic. Biol. Med. 52 (2012) 95-102.

[20] D.A. Hobbs, T.W. George, J.A. Lovegrove, The effects of dietary nitrate on blood pressure and endothelial function: a review of human intervention studies, Nutr. Res. Rev. 26 (2013) 210-222.

[21] P.J. Joris, R.P. Mensink, Beetroot juice improves in overweight and slightly obese men postprandial endothelial function after consumption of a mixed meal, Atherosclerosis 231 (2013) 78-83.

[22] R.A. Harris, S.K. Nishiyama, D.W. Wray, R.S. Richardson, Ultrasound assessment of flow-mediated dilation, Hypertension 55 (2010) 1075-1085.

[23] J.O. Lundberg, E. Weitzberg, NO generation from inorganic nitrate and nitrite: role in physiology, nutrition and therapeutics, Arch. Pharm. Res. 32 (2009) $1119-1126$.

[24] E.A. Skaug, S.T. Aspenes, L. Oldervoll, B. Morkedal, L. Vatten, U. Wisloff, O. Ellingsen, Age and gender differences of endothelial function in 4739 healthy adults: the HUNT3 fitness study, Eur. J. Prev. Cardiol. 20 (2013) $531-540$.

[25] K.E. Lansley, P.G. Winyard, J. Fulford, A. Vanhatalo, S.J. Bailey, J.R. Blackwell, F.J. DiMenna, M. Gilchrist, N. Benjamin, A.M. Jones, Dietary nitrate supplementation reduces the $\mathrm{O}_{2}$ cost of walking and running: a placebo-controlled study, J. Appl. Physiol. (1985) 110 (2011) 591-600.

[26] L.E. Armstrong, C.M. Maresh, J.W. Castellani, M.F. Bergeron, R.W. Kenefick, K.E. LaGasse, D. Riebe, Urinary indices of hydration status, Int. J. Sport Nutr. 4 (1994) 265-279.

[27] D.H. Thijssen, M.A. Black, K.E. Pyke, J. Padilla, G. Atkinson, R.A. Harris, B. Parker, M.E. Widlansky, M.E. Tschakovsky, D.J. Green, Assessment of flowmediated dilation in humans: a methodological and physiological guideline, Am. J. Physiol. Heart Circ. Physiol. 300 (2011) H2-H12.

[28] M. Siervo, J. Lara, I. Ogbonmwan, J.C. Mathers, Inorganic nitrate and beetroot juice supplementation reduces blood pressure in adults: a systematic review and meta-analysis, J. Nutr. 143 (2013) 818-826.

[29] H.K. Engan, A.M. Jones, F. Ehrenberg, E. Schagatay, Acute dietary nitrate supplementation improves dry static apnea performance, Respir. Physiol. Neurobiol. 182 (2012) 53-59.

[30] M. Bahra, V. Kapil, V. Pearl, S. Ghosh, A. Ahluwalia, Inorganic nitrate ingestion improves vascular compliance but does not alter flow-mediated dilatation in healthy volunteers, Nitric Oxide 26 (2012) 197-202.

[31] P. Tripatara, N.S. Patel, A. Webb, K. Rathod, F.M. Lecomte, E. Mazzon, S. Cuzzocrea, M.M. Yaqoob, A. Ahluwalia, C. Thiemermann, Nitrite-derived nitric oxide protects the rat kidney against ischemia/reperfusion injury in vivo: role for xanthine oxidoreductase, J. Am. Soc. Nephrol. 18 (2007) 570-580.

[32] R. Hainsworth, M.J. Drinkhill, Cardiovascular adjustments for life at high altitude, Respir. Physiol. Neurobiol. 158 (2007) 204-211.
[33] C. Sartori, L. Vollenweider, B.M. Loffler, A. Delabays, P. Nicod, P. Bartsch, U. Scherrer, Exaggerated endothelin release in high-altitude pulmonary edema, Circulation 99 (1999) 2665-2668.

[34] M.W. Hoon, N.A. Johnson, P.G. Chapman, L.M. Burke, The effect of nitrate supplementation on exercise performance in healthy individuals: a systematic review and meta-analysis, Int. J. Sport Nutr. Exerc. Metab. 23 (2013) $522-532$.

[35] D.S. Martin, E.T. Gilbert-Kawai, P.M. Meale, B.O. Fernandez, A. Cobb M. Khosravi, K. Mitchell, M.P.W. Grocott, D.Z.H. Levett, M.G. Mythen, M. Feelisch, Design and conduct of 'Xtreme Alps': a double-blind, randomised controlled study of the effects of dietary nitrate supplementation on acclimatisation to high altitude, Contemp. Clin. Trials 36 (2013) 450-459.

[36] J.T. Arnold, S.J. Oliver, T.M. Lewis-Jones, L.J. Wylie, J.H. Macdonald, Beetroot juice does not enhance altitude running performance in well-trained athletes, Appl. Physiol. Nutr. Metab. 40 (2015) 590-595.

[37] B.L. Godber, J.J. Doel, G.P. Sapkota, D.R. Blake, C.R. Stevens, R. Eisenthal, R. Harrison, Reduction of nitrite to nitric oxide catalyzed by xanthine oxidoreductase, J. Biol. Chem. 275 (2000) 7757-7763.

[38] S.K. Ferguson, D.M. Hirai, S.W. Copp, C.T. Holdsworth, J.D. Allen, A.M. Jones, T.I. Musch, D.C. Poole, Effects of nitrate supplementation via beetroot juice on contracting rat skeletal muscle microvascular oxygen pressure dynamics, Respir. Physiol Neurobiol. 187 (2013) 250-255.

[39] O. Frobert, P. Holmager, K.M. Jensen, E.B. Schmidt, U. Simonsen, Effect of acute changes in oxygen tension on flow-mediated dilation. Relation to cardivascular risk, Scand. Cardiovasc. J. 42 (2008) 38-47.

[40] M.M. Berger, C. Hesse, C. Dehnert, H. Siedler, P. Kleinbongard, H.J. Bardenheuer, M. Kelm, P. Bartsch, W.E. Haefeli, Hypoxia impairs systemic endothelial function in individuals prone to high-altitude pulmonary edema, Am. J. Respir. Crit. Care Med. 172 (2005) 763-767.

[41] M. Frick, A. Rinner, J. Mair, H.F. Alber, M. Mittermayr, O. Pachinger, E. Humpeler, W. Schobersberger, F. Weidinger, Transient impairment of flowmediated vasodilation in patients with metabolic syndrome at moderate altitude (1,700 m), Int. J. Cardiol. 109 (2006) 82-87.

[42] A. Ponchia, D. Noventa, M. Bertaglia, R. Carretta, M. Zaccaria, G. Miraglia, P. Pascotto, G. Buja, Cardiovascular neural regulation during and after prolonged high-altitude exposure, Eur. Heart J. 15 (1994) 1463-1469.

[43] C.J. Holloway, H.E. Montgomery, A.J. Murray, L.E. Cochlin, I. Codreanu, N. Hopwood, A.W. Johnson, O.J. Rider, D.Z.H. Levett, D.J. Tyler, J.M. Francis, S. Neubauer, M.P.W. Grocott, K. Clarke, C.X.E.R. Grp, Cardiac response to hypobaric hypoxia: persistent changes in cardiac mass, function, and energy metabolism after a trek to Mt. Everest Base Camp, FASEB J. 25 (2011) $792-796$.

[44] A. Morganti, M. Giussani, C. Sala, G. Gazzano, I. Marana, A. Pierini, M.T. Savoia, F. Ghio, A. Cogo, A. Zanchetti, Effects of exposure to high altitude on plasma endothelin-1 levels in normal subjects, J. Hypertens. 13 (1995) 859-865.

[45] D.F. Wilson, A. Roy, S. Lahiri, Immediate and long-term responses of the carotid body to high altitude, High Alt. Med. Biol. 6 (2005) 97-111.

[46] C.M. Beall, G.L. Cavalleri, L. Deng, R.C. Elston, Y. Gao, J. Knight, C. Li, J.C. Li Y. Liang, M. McCormack, H.E. Montgomery, H. Pan, P.A. Robbins, K.V. Shianna, S.C. Tam, N. Tsering, K.R. Veeramah, W. Wang, P. Wangdui, M.E. Weale, Y. Xu, Z. Xu, L. Yang, M.J. Zaman, C. Zeng, L. Zhang, X. Zhang, P. Zhaxi, Y.T. Zheng, Natural selection on EPAS1 (HIF2alpha) associated with low hemoglobin concentration in Tibetan highlanders, Proc. Natl. Acad. Sci. U. S. A. 107 (2010) $11459-11464$.

[47] N.A. Kametas, M.D. Savvidou, A.E. Donald, F. McAuliffe, K.H. Nicolaides, Flowmediated dilatation of the brachial artery in pregnancy at high altitude, BJOG 109 (2002) 930-937. 